\title{
متطلبات المحاسبية التعليمية \\ في المدارس المتوسطة بالكويت في ضوء التحديات المعاصرة
}

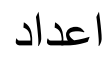

أ.د/ صبري الأنصاري إبر اهيم على

قسم أصول التربية

كلية التربية بقنا

جامعة جنوب الوادي

د/ فاطمة محمد البردويلى

قسم أصول التربية

كلية التربية بقتا فيول التربه

جامعة جنوب الوادي
د/ محمد السيد محمد السيد قسم أصول التربية كلية التربية بقتا جامعة جنوب الوادي

أ/ عبداله محمد عبد الله علي سليمان القصيمى باحث دكتوراه - قسم أصول التربية

كلية التربية بقنا

$$
\text { جامعة جنوب الوادي }
$$


متطلبات المحاسبية التعليمية في المدارس المتوسطة بالكويت في ضوء التحديات المعاصرة

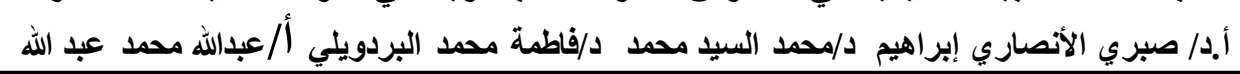

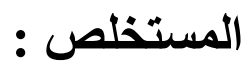
يهدف المقال الى القاء الضوء على متطلبات المحاسبية التعليمية في المدارس المتوسطة بالكويت في ضوء التحديات المعاصرة وذلك من خلال استعراض مفهوم المحاسبية التعليمية واهميتها والاهداف التى تسعى الى تحقيقها كما يوضح العناصر البشرية التي تسهم في تطبيقها ومتطلبات التطبيق في ضوء التحديات المعاصرة وتوصل المقال الى ان هنالك معوقات تحول دون تطبيقها بالشكل المناط الكلمات المفتاحية : المحاسبية التعليمية التحديات المعاصرة المدارس المتوسطةبدولة الكويت 
متطلبات المحاسبية التعليمية في المدارس المتوسطة بالكويت في ضوء التحديات المعاصرة أ.د/ صبري الأنصاري إبراهيم د/محمد السبد محمد د/فاطمة محمد البردويلي أ/عبدالله محمد عبد الله فئه

The article aims to shed light on the requirements of educational accounting in the middle schools in Kuwait in the light of the contemporary challenges

\author{
Prof.Dr.Sabry Alansary Ibrahem \\ Education Assets Department \\ Faculty of Education in Qena \\ South Valley University
}

Dr.Mohamed EISayed Mohamed

Education Assets Department

Faculty of Education in Qena

South Valley University
Dr.Fatma Mohamed EIBardawely

Education Assets Department

Faculty of Education in Qena

South Valley University

\title{
Abdalla Mohamed AbdallaAli Solyman Alksemy \\ Education Assets Department \\ Faculty of Education in Qena \\ South Valley University
}

\begin{abstract}
The article aims to shed light on the requirements of educational accounting in the middle schools in Kuwait in the light of the contemporary challenges by reviewing the concept of educational accounting, its importance and the objectives it seeks to achieve. It also clarifies the human elements that contribute to its application and application demands in the light of contemporary challenges. Prevent their application in the form of a shield

keywords :Requirements Educational Accounting Contemporary challenges Middle Schools in Kuwait Abstract in English
\end{abstract}

العدد السابع والثلاثون


متطلبات المحاسبية التعليمية في المدارس المتوسطة بالكويت في ضوء التحديات المعاصرة

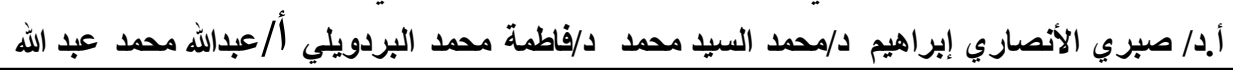

مقدمهة

تتباين وجهات النظر حول مفهوم المحاسبة من حيث أهميتها وأهدافها ومستوياتها وآليات تطبيقها وتوظيفها. وتؤكد جنفر اودي (i) أن هذا الاختلاف مـرده

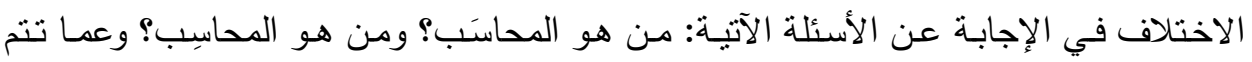
المحاسبةٌ ومـا هي العواقب المترتبة على هذه المحاسبة؛ فنقول مثلا هل تكون المحاسبة من هن هون المعلم إلى الطالب؟ أو من الإدارة المحلية إلى المدرسـة أم من الدولـة إلى الإدارة ؟ كذللك نقول هوله

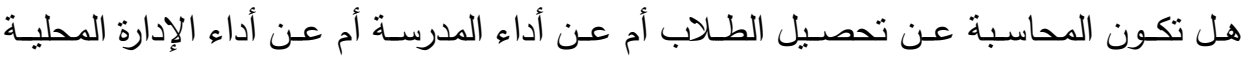

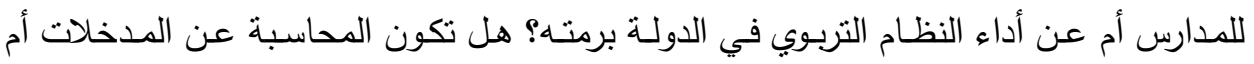

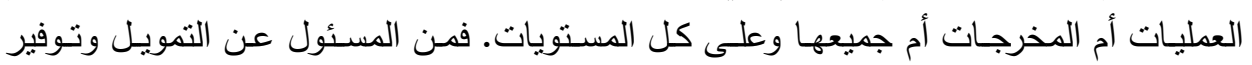

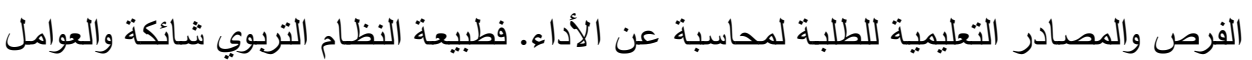
المسئولة عن أداء الطلبـة وتحصسيلهم متعددة. رغم ذلك لابـد من ذكر بعض التعريفات لهذا

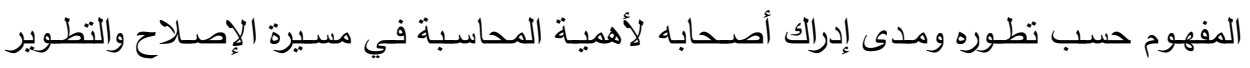
التربوي.

وفى ضوء ذللك اتجهت المؤسسات التربويـة الى تطبيق المحاسبية التعليمية حيث انها تعد أحد الأساليب الفعالة التي تتعرف من خلالها المدرسة على مدى تحقيق معايير جودة الأداء الثامل، فعن طريق المحاسبية يتم تقديم أساليب الثواب التي تعزز أعمال المدرسة نظير تحقيقها لمعايير الجودة، أو تطبيق أساليب العقاب ومطالبتها بمزيد من بذل الجهود اللازمة لتطوير الأداء

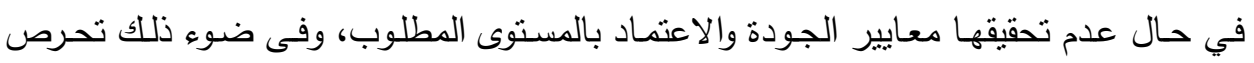

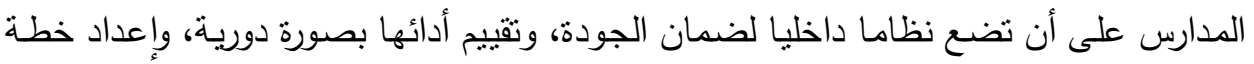
التحسين والتطوير فى ضوء نتائج التقويم الذاتي، وذللك تمهيدا للتقييمات الخارجية التي تستهدف

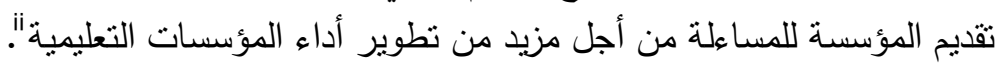
مفهوم المحاسبية التعليمبة: المحاسبية في اللغـة، من الفعل: حاسب، أي: ناقتشه الحسباب. وذللك في معناهـا العام Account، أو بمعناها الخاص Accountability التي تعني المحاسبة عن أعمال معينة نتيجة

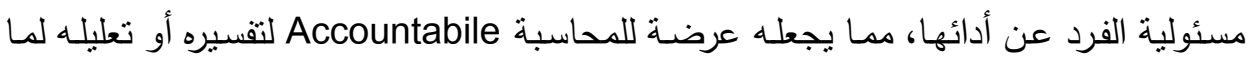
يحاسب عنه. وهي تختلف عن Accounting التي تعني علم فن تدوين الحسابات وتفسيرها من قبل شخص يطلق عليه محاسب Accountant يعتمد في عمله علي ما يتم تسجيله في دفتر (iii) الحساب أو المحاسبة

ويعرفها نيومان وزملاءه (Newman, F.etal) بأنها "عملية تحاول من خلالها إدارة التعليم أو الولاية وغيرهم من ذوي العلاقة بالتعليم التأكد من أن المدارس وإداراتها تحقق أهدافها 
متطلبات المحاسبية التعليمية في المدارس المتوسطة بالكويت في ضوء التحديات المعاصرة

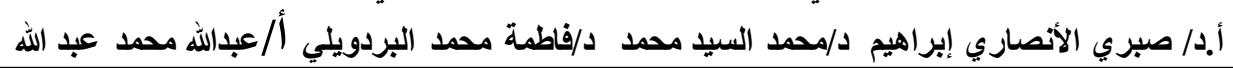

(Ysseldyke, J. et al) تعريفا للمحاسبية التعليمية على انها iv ويقدم يسلدايكي وزمـاؤية "طريقة منظمة وهادفة لطمأنة ذوي العلاقة بالنظام التربوي بأن المدارس تحقق النتائج المرغوبـة، وهي تشتمل على عناصر عامة كالأهداف والمؤشرات على التقدم نحو تحقيق الأهداف والمقاييس

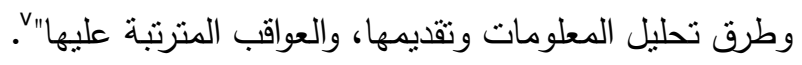
فالمحاسبية ترتكز على عمليـة تقويم الأداء على كل المستويات بـداء بالطالب المـتعلم والمعلم، والمدرسة، ودائرة التعليم المحلية وانتهاء بقمة الهرم للنظام التعليمي بهدف إصلاح النظام وتطويره.فالمساءلة آلية أساسية للتغيير التربوي وهي معنية بكل جوانبه. ونظر إليها البعض على أنها: المجال الذي يكون فيه الفرد مسئولا عن أفعاله أمسام سلطة أعلى سواء أكانت تشريعية أو تتظيمية، وتتضمن أيضا أن يقدم المدير البراهين على أن البرامج التي اتبعها قد اتسقت مـع الأهداف الموضـوعة وأسـهت بفاعلية في تحقيقها(vi). وترى " رانيا عبد المعز 9 . . rام " أن المحاسبية التعليمية هي آلية من آليات جودة التعليم تهدف إلي تطوير التعليم من خلال هيئة مسئولة عن مراقبة الجودة، ومراجعة ومحاسبة جميع المسئولين عن العملية التعليمية في ضوء معايير تضعها الهيئات المنظمة من أجل التحسين المستمر كضرورة

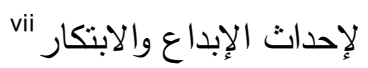
أهداف المحاسبية التعليمية الإعاع إن نظام المحاسبية ليس هدفا في حد ذاته، بل هو وسيلة لتحقيق غايات عليا يريدها أفراد المجتمع ويضمونها سياستهم التعليمية، تستهدف في النهاية تحسين العملية التعليمية وتطويرها لتواكب المعايير التي يفرضها السوق العالمي، مثل تأكيد القدرة علي المنافسـة والارتقاء بـالأداء التعليمي وتجويــ نتائجسه. وبمراجعـة الأدبيـات التـي تتاولت نظـام المحاسـبية في التعليم قبـل الجامعي، فإن الغايات والأهداف التي تكمن وراء استخدامه في العملية التعليمية يمكن إبرازها في ما يلي • التأكد من أن السلطات الممنوحة للمدرسة تستخدم في إطارها الصحيح ولا بياء استعمالها وبالنالي تكون المحاسبية وسيلة للرقابة علي مستوى الأداء. الارتقاء بمستوى أداء المدرسة، وكذلك أداء العاملين فيها مما بضمن التحسين المستمر للأداء علي مستوى الفصل والمدرسة وتطويره في المستقبل، بما ينعكس علي جودة عمليتي التعليم والتعلم. 
متطلبات المحاسبية التعليمية في المدارس المتوسطة بالكويت في ضوء التحديات المعاصرة

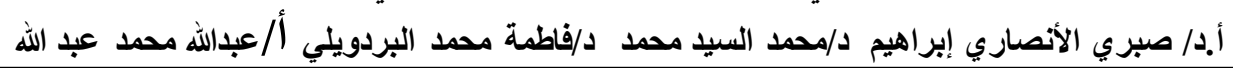

تقديم المعلومات الأساسية عن الدور التعليمي للمؤسسات التعليمية للحفاظ علي الجودة المطلوبة، وتحسين الإنتاجية، وتقديم معلومات تساهم في في تتخيص وتحلئ الإسيل الأداء التعليمي للمؤسسة التعليمية. إيجاد أساليب تقويم أكثر فاعلية وشمولية تساعد علي تقرير مدى صلاحية الطلاب للالتحاق بالتعليم الجامعي وفي تخصصات معينة أو صلاحيتهم لسوق العمل وفي مهن معينة. مساعدة المدرسة علي تطوير نفسها ذاتيا لتحقيق التميز والتفوق بين المدارس الأخرى، وتزويد المستفيدين بالمعلومات.

(المحاسبية كنوع من الضمان)، أي توفير الضمان الكافي بأن السلطة الممنوحة لأفراد

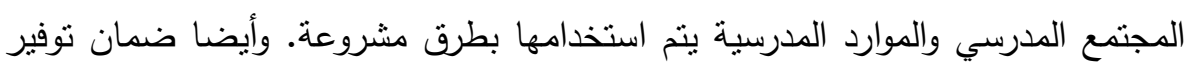

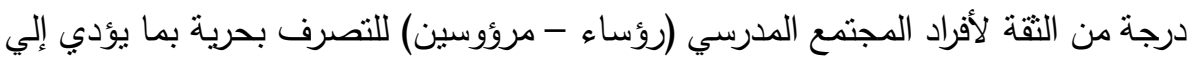
تطوير الأهداف المدرسية وضمان توفير أفضل الخدمات. تقديم معلومات عن الأداء التعليمي، بحيث تناهم تلك المعلومات في تقديم تغذية راجعة

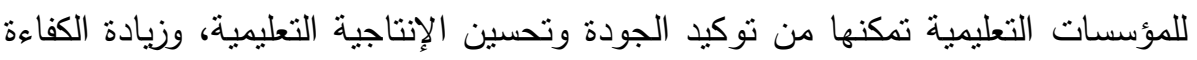
والفاعلية التعليمية لها. تقديم الحلول للمدارس التي فثلت في تحقيق الأهداف لعلاج جوانب الضعف والقصور. العناصر البشرية التي يشملها نظام المحاسبية:

تتعدد وتتتوع وتختلف مهامها ومسئولياتها في نظام المحاسبية، وذلك علي النحو النتالي أنية:

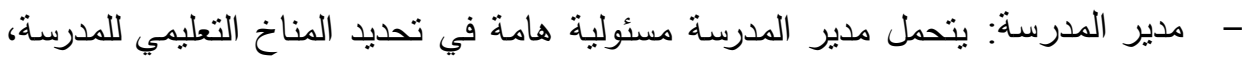

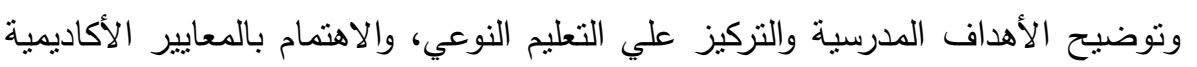
والسلوكية التي يفترض أن يصل إليها الطلبة، وتقديم الدعم لاستمرار التطوير والتربية

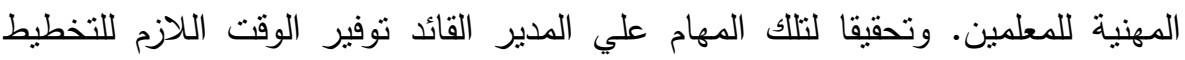

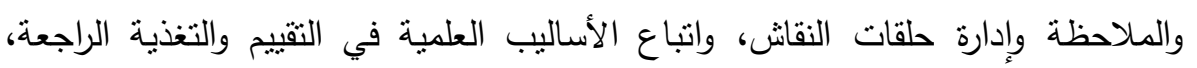

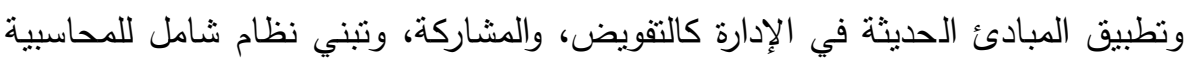

$$
\text { علي نطاق المدرسة. }
$$

- - الطالب: تتمتل مسئولية الطالب في الالتزام بالحضور إلي المدرسة يوميا، وأن يكون مستعدا

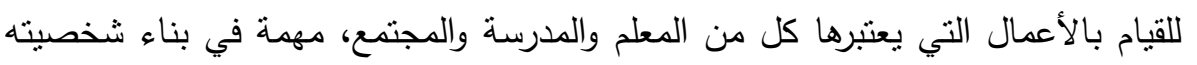

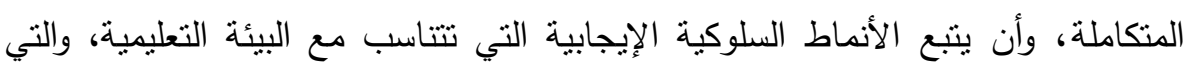
يتوقعها منه المجتمع. 
متطلبات المحاسبية التعليمية في المدارس المتوسطة بالكويت في ضوء التحديات المعاصرة

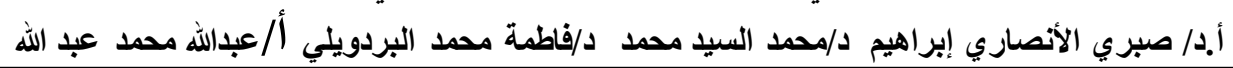

- - المعلم: تتمنل مسئولية المعلم في المقدرة علي توفير العمل الأكاديمي الفعال للطلبة، وإيجاد

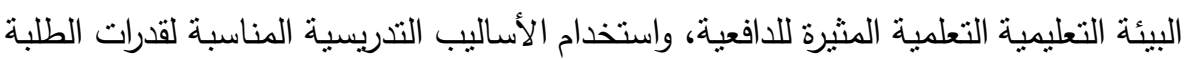
والاهتمام بالتزود بالخبرات التربوية الحديثة في مجال التدريس وكيفية التفاعل مع الطلبة.

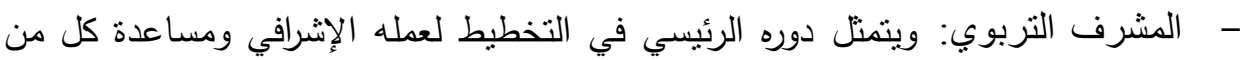

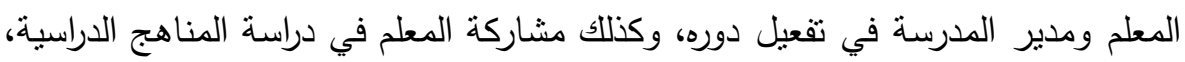

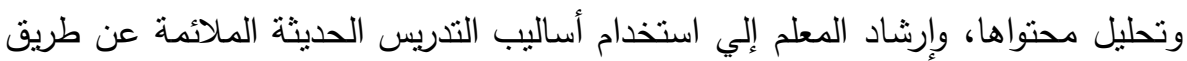
إعداد وتتفيذ الدروس النطبيقية، وتظهر مسئولية المشرف التربوي في مشاركة المعلم في

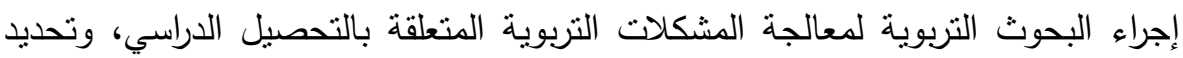
حاجات التربية المهنية للمعلمين المستمرة وتوجيههم نحو ممارسة التقييم الذاتي x. - - أولياء الأمور : ويتمثل دورهم في تكوين التوقعات الأكاديمية والسلوكية التي تقود أبنائهم أثثاء تفاعلهم في البيئة المدرسية، إذ أن المفاهيم الإيجابية أو السلبية التي تنباها الآباء ويعكسها لغالياه

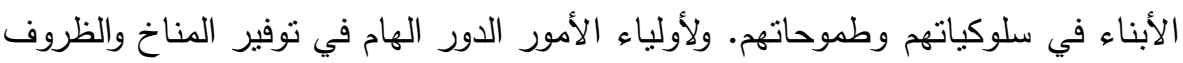

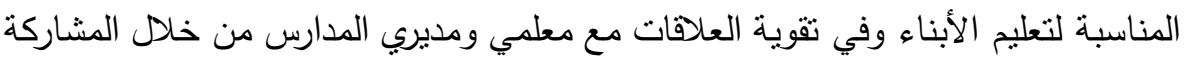

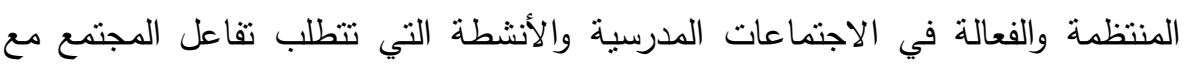

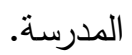
- - مديرية التربية: وتقع عليها مسئولية الإثراف علي العملية التعليمية التعلمية في المدارس التي تقع ضمن إثرافها، وتقديم الدعم المادي والمعنوي لها، والمتمثل في توفير الهيئة التعليمية المناسبة، والموارد والتجهيزات التي تساعد علي عملية تعليم الطلبة وتعلمهم، ومراقبة سير الإدارة المدرسية وقيامها بالمهام المنوطة بها، والمساعدة في معالجة القضايا

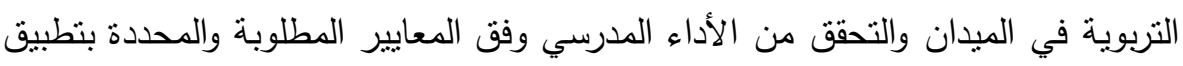
نظام مساءلة المدارس ومراقبة التقدم السنوي المستمر للطلبة فيها. خطوات و إجر اءات المحاسبية التعليمية:

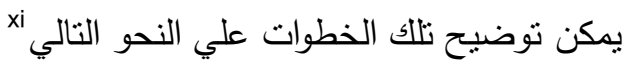
(1) تحديد الأهداف العامة والإجر ائية: وداخل بنية المحاسبية تؤسس الأهداف العامة والإجرائية

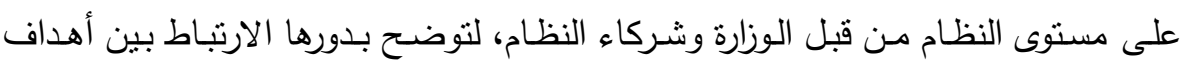

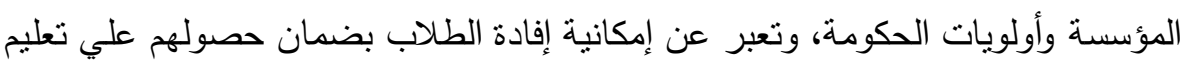
عالي الجودة وفرص تعليمية ملائمة لاحتياجاتهم ومنطلبات سوق العمل. وتؤدي الأهداف 
متطلبات المحاسبية التعليمية في المدارس المتوسطة بالكويت في ضوء التحديات المعاصرة

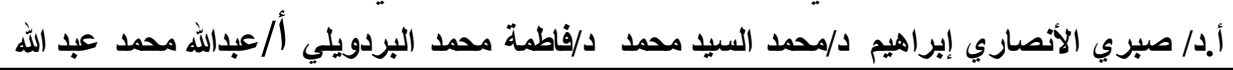

وظيفة نوضيح الاتجاه الاستراتيجي لعمل أنظمة المحاسبية، وفي نظام المحاسبية يجب أن تكون الأهداف العامة والخاصة مثرابطة ومنسجمة، أن تكون واضحة وهادفة وقابلة للقياس.

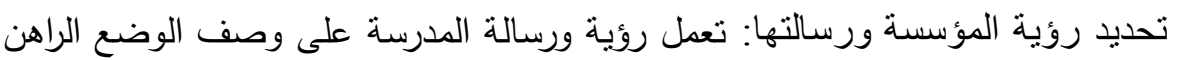

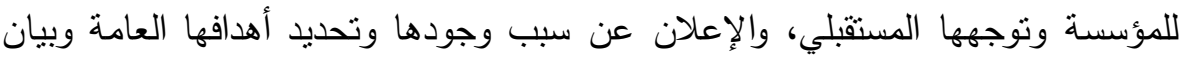
الأنثطة الموجهة نحو إنجاز هذه الأهداف كمنطق لبناء نظام للمحاسبية، لذا يجب ونب أن يتن صياغتها وتحديدها في ضوء تحليل الييئة الخارجية وما يظهره من فرص محتملة وتهديدات كافية وتحليل البيئة الداخلية وما يظهره من جوانب قوة وجوانب ضعف، بالإضافة إلى فلسفة

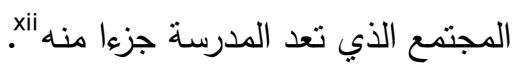

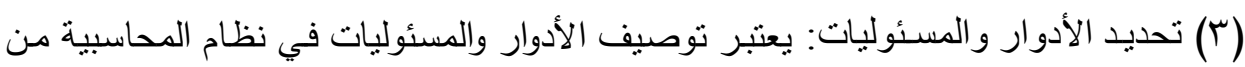

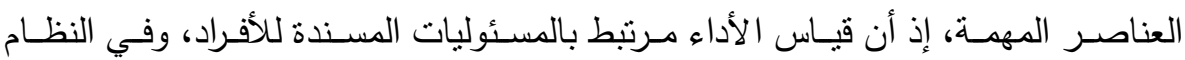

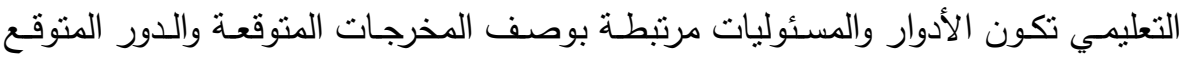

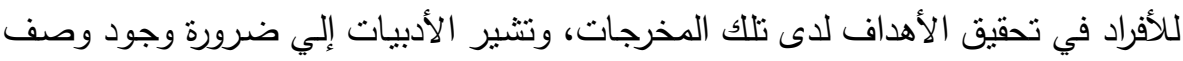
وتحديد للأدوار التي يشغلها الأفراد في المؤسسات التعليمية تتضح فيها المهام والمسئوليات.

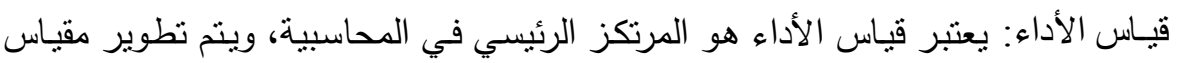

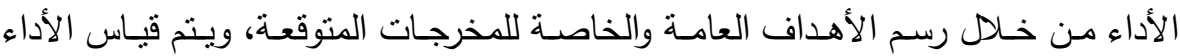
بمعايير ومؤشرات معينة، تتفق مع أهداف النظام التعليمي والمستوى الذي ينشد الوصول إليه

(0) نقـارير الأداء: وتشـمل تقارير المحاسبية علي مستوى المدرسـة بيـان المعلومات الخاصـة

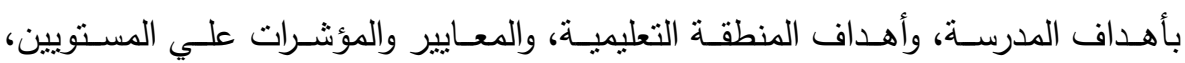

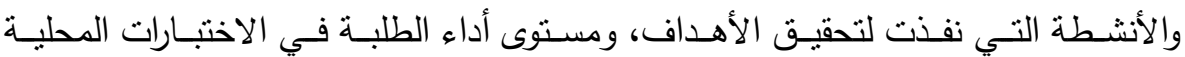

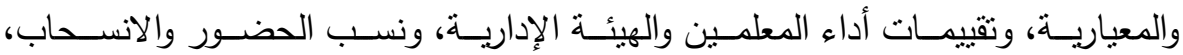

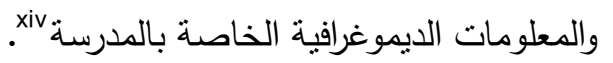

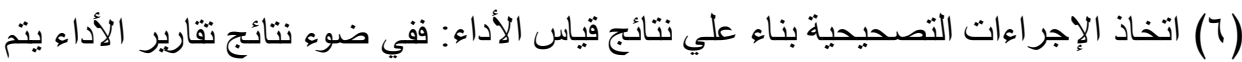

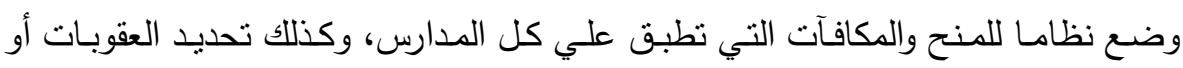
الجزاءات التي تطبق علي المدارس التي لا تصل إلى مستوى المعايير الموضوعة ولا تحقق

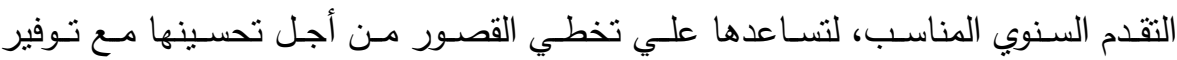

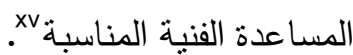


متطلبات المحاسبية التعليمية في المدارس المتوسطة بالكويت في ضوء التحديات المعاصرة

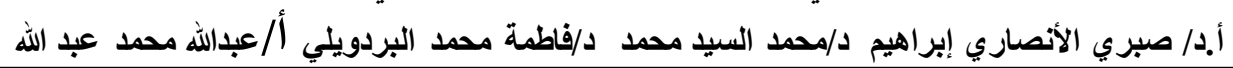

المحاسبية التعليمبة فى ضوء المتغير ات المعاصرة : للمتغيرات المعاصـرة العديــ مـن الإيجابيـات التى يمكن الاسـفادة منهـا فـى الكثير مـن المجالات وخاصة فى المجال التربوى والتعليمى ـ الأمر الذى يضفى على هذه المتغيرات أهمية

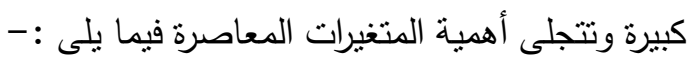

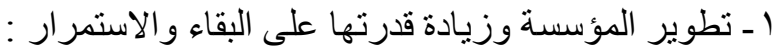

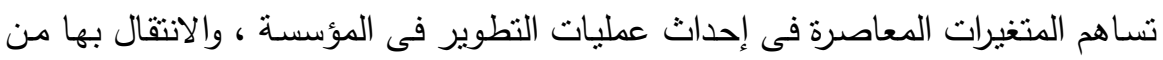
الوضـع الحـالى إلـى وضـع مسـقبلى أكثر كفـاءة وجـودة وفاعليـة ، فـالمتغيرات لكونهـا تشـكل (عنصر تحدى) تتطلب مواكبتها أو مواجهتها والتصدى لها ، ومثل هذه العمليات يتبعها حدوث تغيير وتطوير فى المؤسسة سواء أكان تغيير جزئى أو تغيير شامل بحيث يتماشى هذا التغيير مع طبيعة العصر والاستجابة بشكل أفضل لمنطلباته ومقتتياته وتحدياته . " وأثـارت إحـدى الدراسـات إلـى أهميـة المتغيـرات المعاصـرة فـى نزايـــ سـرعة التغييـر

الاجتماعى وتعرض القيم والمعايير والنظم والمؤسسات لعمليات التغيير والتحول " ( )

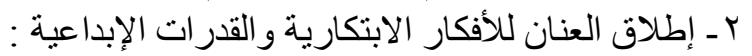

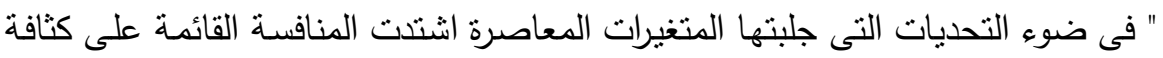
التجديد سـواء بـين الـدول أو المنظمـات المختلفـة ، أو بين القطاعـات المختلفـة داخل المنظمـة الواحدة مدـا أتـاح الفرصسة للمسـاهمة فى تقديم المبـادرات والمقترحسات والحلـول لمواجهـة هـذه التحديات وسبل التعامل معها ، وسـاهم هذا المناخ فى زيادة الحاجـة إلى قوة الإبداع والتجديد وإطلاق العنان للأفكار الابتكارية ، والقدرات الإبداعية لكونهما الوسيلة الوحيدة للبقاء والرخاء فى ظل التتافسية العالمية ـ الأمر الذى ساهم فى ظهور الاختراعات وتحقيق الثراء الفكرى والثقافى اهى

(r) ."

بـ القضاء على عو امل العزلة ، وإز الة الحو اجز بين المجتمعات واستثمار الوقت والجهد :

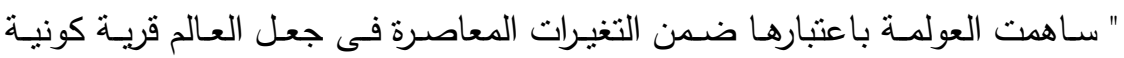
يتصل أهلها فى سهولة ويسر ، وأسقطت الحواجز والحدود والمسافات بين الدول وشعوب العالم المختلفة ـ الأمـر الذى سـاهم فى القضـاء على عوامل العزلـة ، ويسرت عمليات الانفتاح على

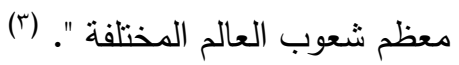
وكذلك ساهمت " الثورة التكنولوجية " فى نوفير الوقت والجهد وضمان الإشراف بفاعلية على أعداد كبيرة من القوى البشرية . عـ تطبيق الأسلوب العلمى فى التخطيط : 
متطلبات المحاسبية التعليمية في المدارس المتوسطة بالكويت في ضوء التحديات المعاصرة

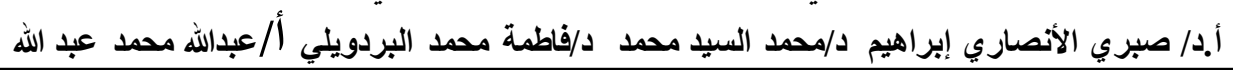

" فى ضـوء المستجدات التى فرضتها المتغيرات المعاصرة فإن الأمر يحتم وضع رؤيـة مستقبلية شاملة للتعامل مع هذه المتغيرات من خلال التخطيط الواعى الاقيق ، ورسم السياسات

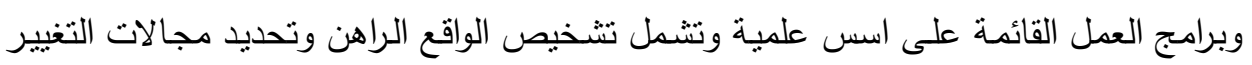

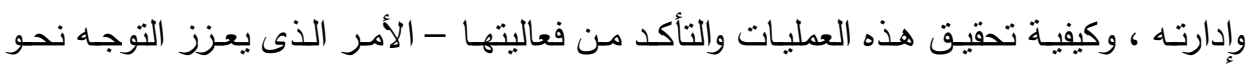

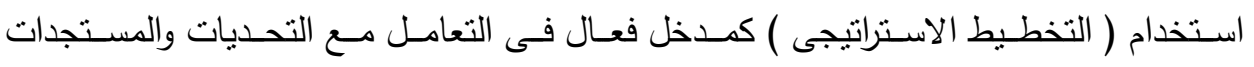

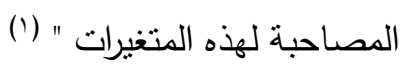

ـ ـ تغيير الأهمية النسبية لقوى العمل ، و علاقات الإنتاج :

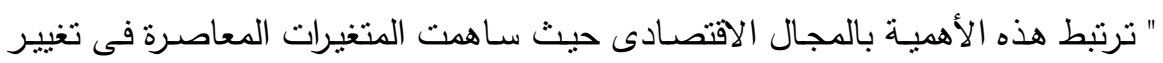

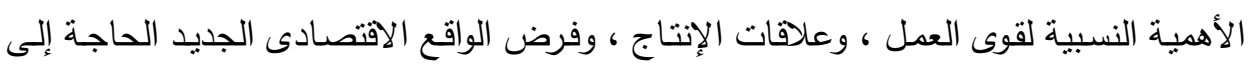

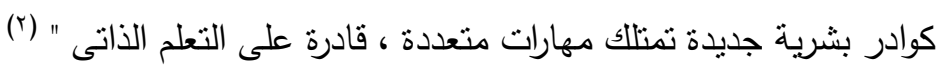

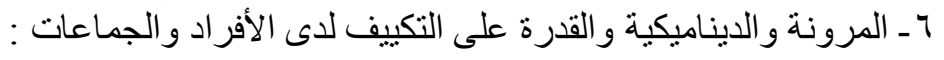

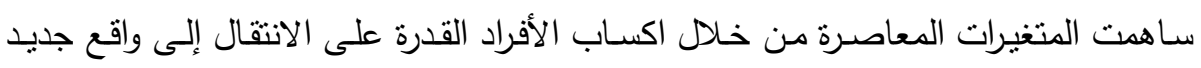
يتمشى مـع طبيعة العصر ومتغيراته ويستجيب لمقتضياته ويتكيف مع المستجدات التى جلبتها

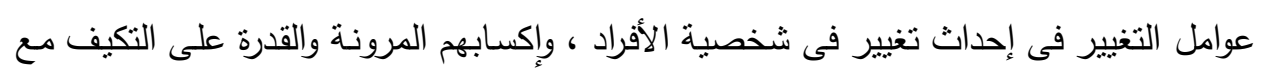
هذا الواقع الجديد . وامتدت أهمية المتغيرات المعاصرة إلى المجال التربوى والتعليمى ، وساهمت بدور كبير

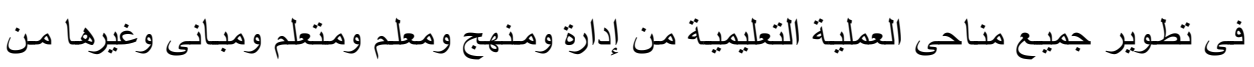

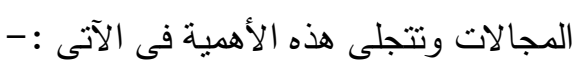

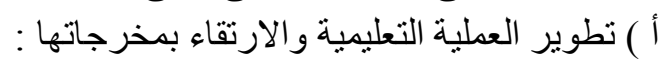
يتحقق ذللك من خلا الدور الذى تلعبه ثورة المعلومات وتطور التكنولوجيا في التطوير

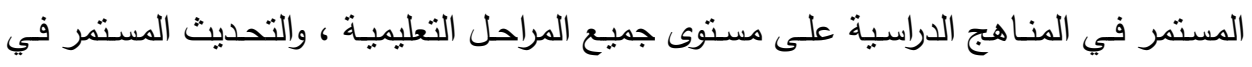

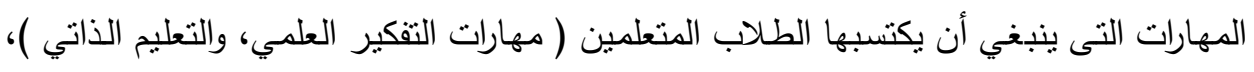

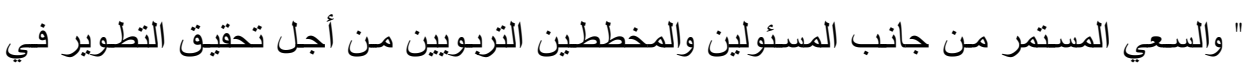

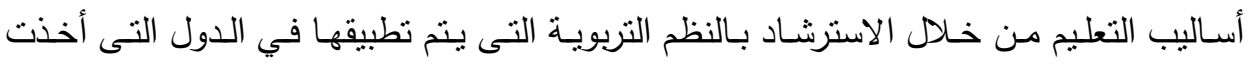
بأسباب التقدم وانعكاس ذلك التقدم على جوانب حياتها حيث اقترنت المتغيرات ( بالعالميـة ) 
متطلبات المحاسبية التعليمية في المدارس المتوسطة بالكويت في ضوء التحديات المعاصرة

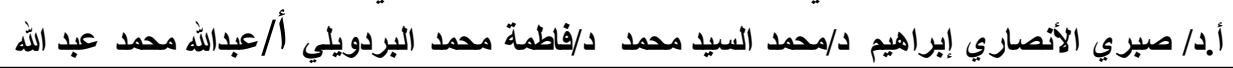

وأيضاً ( بالمعاصرة) الأمر الذى ساهم في تحقيق الجودة ، وتقديم مخرجات تعليمية تواكب هذه المتغيرات، وتحـاول اللحاق بالمستجدات التى طرأت على العملية التعليمية " (') وبذلك تسـهم ( المتغيرات ) في التغلب على الروتين التقليدي الذـى تـدار بـه معظم المـدارس الحاليـة ، وفىى مساعدة هذه المدارس على تحقيق أهدافها واهمها تخريج جيل من المتعلمين واع بما يدور حوله

، مدرك بمسئولياته في مواجهة التحديات التى خلقتها العولمة والثورة المعلوماتية التكنولوجية .

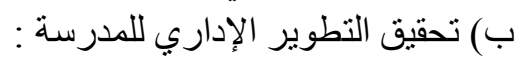
في ضوء التحديات التى فرضتها المتغيرات المعاصرة بات من الضروري إعادة تطوير النظم الإداريـة الحاليـة في جميع المراحل الدراسية وبمـا يجعلها مضطرة للتكييف مـع التغييـر ومسـايرته، والخـروج بالعمليـة الإداريـة مـن موقـع التقليد إلى موقـع التغييـر ، وأصـبح اسـتخدام التكنولوجيا ضرورة ملحة لضمان الإشراف الإداري بفاعلية على أعداد كبيرة من القوى البشرية العاملة بالمدرسة من إداريين ومعلمين وطلاب ، ومتابعة أعمالهم ، فضلاً عن توفير واستثمار الوقت والجهد بفاعلية . باهن

وصحب هذه المتغيرات ميلاد أنظمة جديدة تتواكب مع إيقاع العصر كالإدارة بالأهداف

والإدارة بالتقنية ، وإدارة الجودة الثاملة وغيرها من الأنماط الإدارية الحديثة والمعاصرة "(ب)

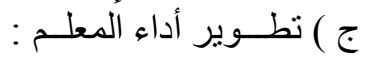
جاءت المتغيرات المعاصرة آثار ومضامين تربوية عميقة ذات صلة وثثقة بأدوار المعلم

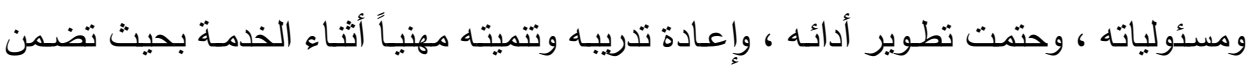
التتميـة المهنيـة ببرامجها وآلياتهـا مستوى رفيع الأداء للمعلم ، وتمنحـه القدرات التى تمكنـه من المساهمة في تحقيق أهداف التعليم ، والتعامل الجاد مع معطيات عصر العولمة ، والاستفادة من لـاءن الإيجابيات التى جلبتتا الثورة المعلوماتية والتكنولوجية وتوظيفها لصالح تطوير أداء المعلم. د) تمكين القيادات المدرسية من تطوير أدائها و إكسابها المهار ات القيادية وتئة الحديثة : فرضـت المتغيـرات المعاصـرة باعتبارهـا نشـكل فرص وتحـديات سـمات جديـدة للمـدير العصري الناجح ، فالإيقاع السريع الذى نتسم بـه جميع مجالات الحياة ، والتطوير الهائل في شكل ومضمون البرامج الإليكترونية يقتضى إلمام مدير المدرسة بالمهارات والخبرات التى تمكنه من استخدام هذه البرامج وتوظيفها في الحصول على المعلومات التى تمكنسه من إيجاد حلول مناسبة للمشكلات الإدارية والتربوية التى تعانى منها المدرسة . وفرضت هذه التحديات على مدير المدرسة التحديث المستمر لمهاراته وخبراتـه وبمـا يمكنه من مسايرة عوامل التطوير الذى أحدثته هذه المتغيرات، والتعامل بايجابية ووعى مع كل ما 
متطلبات المحاسبية التعليمية في المدارس المتوسطة بالكويت في ضوء التحديات المعاصرة

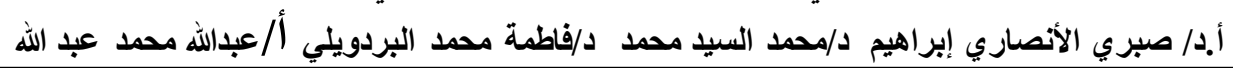

يدور حوله من أحداث ، واستثمار الفرص التى جلبتها العولمـة والثورة المعلوماتية وتسخيرها في إصـلاح البيئة المدرسية بكل عناصرها ومقوماتها ، والبحث عن الأفضل وإثارة كوامن الإبـداع والابتكار في البيئة المدرسية .

" وساهمت هذه المتغيرات في إضـافة ادوار جديدة لمدير المدرسـة العصري بـأن يكون مؤمنـاً بـالتطوير ، ومساهماً ومشـاركاً ومنفذاً له ، وأن يدرج هذا ( التطوير ) ضمن استراتيجية

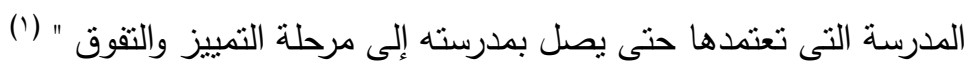
هـ) خلق منافسة مدرسية جديدة تو اكب متغير ات العصدر : " سـاهمت المتغيرات المعاصرة في إيجاد ثقافـة مدرسية جديدة تفيد القائمين على التعليم ، وأفراد المجتمـع المدرسـي في التعامل مـع معطيات العصر ومـا بحمله من متغيرات ، وتشـعرهم بحريـة المشـاركة الفكربـة والعملية ، والقدرة على حل المشكلات ، واسنتـراف المستقبل ـ الأمـر الذى ساهم في زيادة حماسهم ودافعيتهم للعمل " (r) . في ضـوء مـا سبق عرضـه مـن جوانب مختلفة توضـح أهميـة المتغيرات المعاصـرة يـرى الباحث أن المتغيرات المعاصـرة أصبحت ( واقع ) لا محالة ، وسمة مميزة من سمات العصر الحالي الذى تتسارع فيه سبل التغيير التى فرضنتها طبيعة العولمة ، والثورة المعرفية والتكنولوجية وغيرهـا من المتغيرات التى كان لها تأثيرات واضـحة في مختلف مجالات الحياة وخاصـة في المجال التربوى والتعليمي - الأمر الذى يتطلب أن تتتهج الأنظمة المدرسية أسلوب التخطيط الواعي لمواجهة التحديات التى فرضتها هذه المتغيرات ، والاستفادة من الفرص الإيجابية التى جلبتها وتوظيفها لصالح المجتمع ومؤسساته وأفراده .

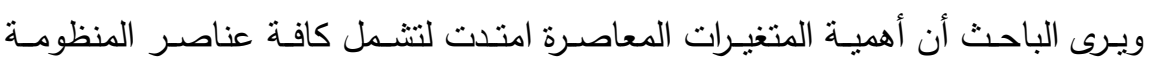
التعليمة من مدرسة ومعلم ومتعلم وإدارة . وهذا يعد أمر طبيعي فالتغيير الذى يصيب أي جانب

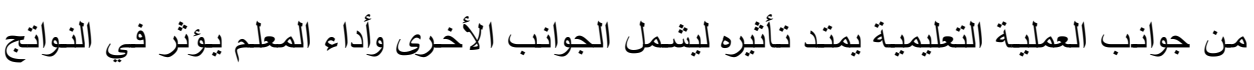
التعليميسة للطسلاب ، والإدارة المدرسية الفعالـة القادرة على عـلاج المشكلات المدرسية يـعكس تأثيرها إيجابياً على كل من المعلم والتلميذ والعملية التعليمية برمنها . ويرى الباحث أن أهمية المتغيرات المعاصرة كثيرة ، وعديدة وابرزها خلق مداخل وأنماط إدارية حديثة قادرة على الصمود أمام التحديات التى جلبتها هذه المتغيرات ، وعلاج المشكلات المدرسية التى تراكمت في ظل النظم الإدارية التقليدية العتيقة . 
متطلبات المحاسبية التعليمية في المدارس المتوسطة بالكويت في ضوء التحديات المعاصرة

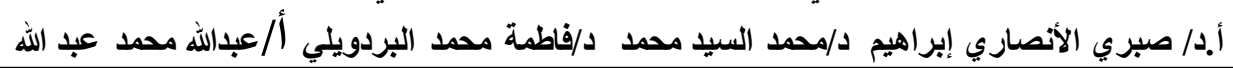

كذلك يعد تطوير أداء العناصر البشرية والقياديـة من معلمين ومدراء ، وإعادة تدريبهم وتتميتهم وبما يضمن لهم مستوى رفيع الأداء ، وقدرة على التعامل مع تقنيات العصر من أبرز الإيجابيات الناجمة عن هذه المتغيرات والتي تضفى عليها أهمية كبيرة .. معوقات تطبيق المحاسبية التعليمية في المدارس المتوسطة من اهم المعوقات أسباب العجز الإداري وجود التعقيد والازدواجية ، وعدم الانضباط ، وشيوع الأمراض الإداريـة المتمنلـة في المحسـوبية والواسـطة والمحابـاة ، والتي تحمل عمليـة معالجتهـا معاني هامـة ؛ منها مـا يـدل على عدم الرضـا من قبـل القيادات السياسية أو الإداريـة عن أداء الجهاز الإداري كماً ونوعاً ، ويشكل هذا في حد ذاته تأكيداً لإدراك الدور السلبي الذي تلعبـه الإدارة العامـة بالرغم من أهميتها وإيجابياتها الكثيرة في إدارة الشؤون العامـة ، وقد تأكد الثـعور

بأن إخضاع الجهاز الإداري للمساءلة يشكل ضماناً لتحقيق الأهداف المتوخاة من وجوده ( '). ومن اهم هذه المعوقات بالمدارس المتوسطة بدولة الكويت التالى : - - سيادة المركزيـة الثـديدة : ويـؤدي هذا إلى جعل الإداريين منفذين لمـا يملي عليهم مـن رؤسائهم ، وعدم منحهم للصدلاحيات ، مما بضعف قدرتهم على مساءلة المرؤوس ، وبالتالي تحد مـن عمليـة المحاسبية ؛ باعتبـار المحاسبية عمليـة تشـل جميـع جوانب العمليـة الإدارية ، والتي تتطلب من الإداري استخدام مهاراته وجدارته في العمل ، ومحاولته الابتكار ، ولهذا يكون المسوغ الرئيس أن التعليمات تقتضي ذلك ، وهو ينفذها فقط. - - ضـعف التخطيط الثـامل : ويتسـبب في إضـعاف ، أو إهمـال الاستخدام الأمثنل للطاقـات التتظيمية ، وهذا يؤدي إلى عدم تحديد الأدوار بدقة وبالتالي تحدث الازدواجية والتداخل في

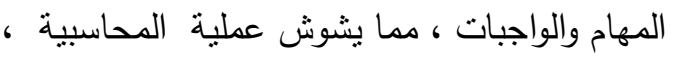
- - صعوبة تفعيل الرقابة والإشراف الإداري - ضعف الحماية الممنوحة للأشخاص والوحدات الإدارية : وتتمثل بقلة الضمانات الممنوحة للهيئات التي تمارس أعمال الرقابة والمنابعة و المحاسبية . - وجـود ولاءات اجتماعيـة وقبيلـة تقليديـة : وهذه تؤدي إلى شيوعية المحسـوبية في عمل الإدارة، وتحول في طبيعة العلاقات بين العاملين. - الاتجاهات السلبية : وتتمنل بالمواقف والسلوكيات السلبية من العاملين نحو المحاسبية . 
متطلبات المحاسبية التعليمية في المدارس المتوسطة بالكويت في ضوء التحديات المعاصرة

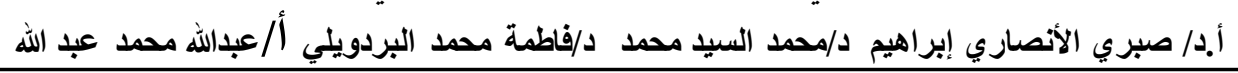

جمهورية مصر العربية، الهيئة القومية لضمان جودة التعليم والاعتماد: دليل الممارسات المتميزة

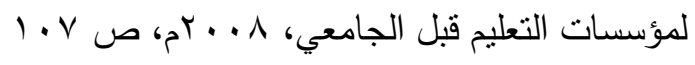
مجدي صلاح طه: المساعلة التعليمية في مصر بين إثكاليات التنظير وممارسات النطبيق في ضوء صواء

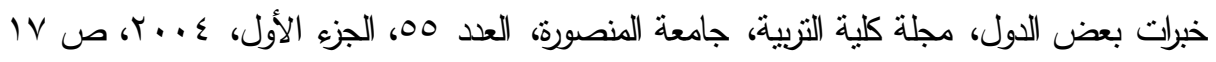

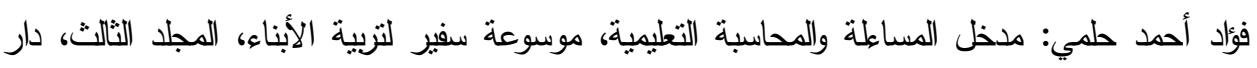

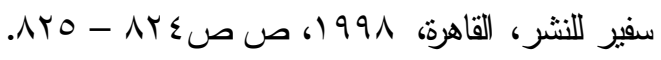


متطلبات المحاسبية التعليمية في المدارس المتوسطة بالكويت في ضوء التحديات المعاصرة أ.د/ صبري الأنصاري إبراهيم د/محمد السبد محمد د/فاطمة محمد البردويلي أ/عبدالله محمد عبد الله فئه

رانيا عبد المعز الجمال: دراسة مقارنة لنظم المحاسبية التغليمية في كل من استراليا وانجلتزا ونيوزلندا،

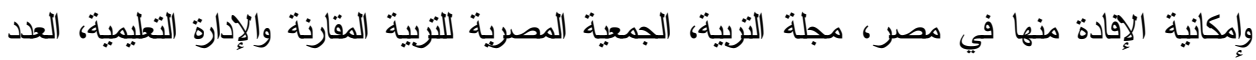

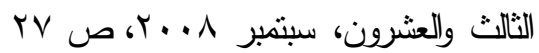

هاني عبد الرحمن الطويل: التقبيم والمساعلة كمدخل في إدارة النظم التربوية، بيروت: الهيئة

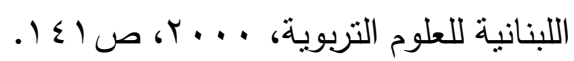

إيمان أحمد محمد عزب: تطوير نظام تقويم الأداء الوظيفي بالمدرسة الثانوية العامة في جمهورية مصر العربية في ضوء مدخل إدارة الجودة الثاملة، رسالة ماجستير غير منشورة، كلية التربية،

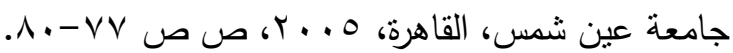

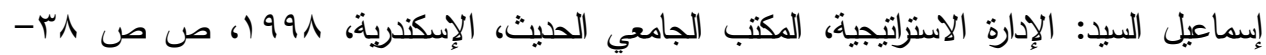
.$r q$

O' Day, Jennifer (2000) "Complexity, Accounta - bility, and School Improvement". Harvard Educational Review. Vol. 72, No. 3, pp. 293 $-329$

Newman, Fred. etal. (1997) "Accountability and School Performance; Implication from Restructuring Schools" Harvard Education Review. Vol. 67، No.1, p. 43

Ysseldyke, J. etal. (1998). "NCEO Framework for Educational Accountability". National Center on Educational Outcomes. http://education.umn.edu / NCEO /onlinepubs / Framework.htm1. p.4

Daniel L. stufflebeam and David Nevo, Evaluation of Educational Personnel, In Torstein Husen and T. Neville Postlethwaite (Editors), The International Encyclopedia of Education, 2th Edition, Vol.4, (Oxford: El Sevier Science Ltd, 1994), pp.21 - 24.

العدد السابع والثلاثون


متطلبات المحاسبية التعليمية في المدارس المتوسطة بالكويت في ضوء التحديات المعاصرة أ.د/ صبري الأنصاري إبراهيم د/محمد السبد محمد د/فاطمة محمد البردويلي أ/عبدالله محمد عبد الله فئه

Karen Cullen, Literature Review Findings: Evaluation of Superintendents, Encyclopedia Journal of Personnel Evaluation In Education, vol 9, No.4, 1995, pp.352-355.

Goff، John M ; Amore comprehensive Accountability Model. Retrieved November 16، 2000。 from http://www.c_b_e.org/articles/Goff.htm .

L.H. Browder، "Accountability ; forms and policies "، International Encyclopedia of Education، Vol.1، 2000.P. 22.

Ministry of Advanced Education ; An Accountability Framework for British Columbia's Public Post - secondary education system، Council of Chief State School Officers

Pennsylvania State System of Higher Education: Accountability and Performance Funding، Spring 2005، p p.1-6

Kenneth Leithwood ; Educational Accountability: Issues and Alternatives، Saskatchewan School Boards Association، Research Report، May, 2005 p 51.

Davis، Michael.J، et al: New Mexico Public School Accountability System، New Mexico، The New Mexico State Department of Education، 2003، p p 5-7. 